\title{
Effect of post-exercise drink composition on appetite and energy intake
}

\author{
David J. Clayton, David J. Stensel, Phillip Watson and Lewis J. James \\ School of Sport, Exercise and Health Sciences, Loughborough University, Loughborough, Leicestershire, LE11 3TU, UK
}

A liquid protein preload has generally been shown to decrease energy intake at an ad libitum meal compared to water ${ }^{(1)}$ or an isoenergetic carbohydrate preload $^{(2)}$. However this has not been investigated in conjunction with exercise. Ingestion of protein and carbohydrate drinks post-exercise has become common practise amongst athletes and physically active individuals and their effects on appetite and energy intake is of interest, particularly to those on a weight management programme. To investigate whether protein induced satiety was evident when drinks were ingested in a post exercise context; the present study compared two isoenergetic drinks, differing in macronutrient content, and a low energy placebo drink.

Using a randomised double blind, counterbalanced design, 9 healthy males completed 30 min continuous cycling exercise at 63 (4) $\%$ $\mathrm{VO}_{2}$ max, followed by five, $3 \mathrm{~min}$ intervals at 86 (4) \% $\mathrm{VO}_{2}$ max, separated by 2 min rest. 10 min post-exercise, subjects ingested $500 \mathrm{ml}$ of one of three drinks each made up with low-energy lemon squash: a placebo drink (PLA) ( $15 \mathrm{~kJ}, 0.3 \mathrm{~g}$ protein, $0.6 \mathrm{~g}$ carbohydrate); a whey protein isolate drink (PRO) $(528 \mathrm{~kJ}, 30.3 \mathrm{~g}$ protein, $0.6 \mathrm{~g}$ carbohydrate, $0.1 \mathrm{~g}$ fat $)$; a sucrose drink $(\mathrm{CHO})(528 \mathrm{~kJ}, 0.3 \mathrm{~g}$ protein, $30.8 \mathrm{~g}$ carbohydrate). This drink was ingested from an opaque bottle and through a straw. 60 min post-drink ingestion, subjects were provided with a homogenous ad-libitum lunch, consisting of pasta, cheese, tomato sauce and olive oil $\left(1.88 \pm 0.03 \mathrm{kcal} \cdot \mathrm{g}^{-1}\right)$. Visual analogue scales of appetite ratings (hunger, fullness, desire to eat, prospective food consumption, satisfaction) were completed pre-exercise, postexercise, post-drink, pre-meal, post-meal, $30 \mathrm{~min}$ post-meal and $60 \mathrm{~min}$ post-meal. Drinks were rated for sensory characteristics (pleasantness, after taste, saltiness, bitterness, sweetness, creaminess, refreshing, thickness, stickiness, fruitiness) immediately post-ingestion.

Energy consumed at the ad libitum lunch was lower after PRO ingestion (5732 (959) kJ) than PLA ingestion (6398 (497) kJ) $(P=0.025)$, but was not different after CHO ingestion $(6137(1041) \mathrm{kJ})$ compared to either PRO $(P=0.747)$ or PLA $(P=0.889)$ ingestion. When the energy content of the drink ingested was added to the energy consumed at the ad libitum meal there was no difference between the trials (PRO: 6270 (959) kJ, PLA: 6413 (497) kJ, CHO: 6665 (1041) kJ; $P=0.302$ ). There were no main effects of trial $(P>0.05)$ interaction $(P>0.05)$ for any of the measured subjective appetite ratings. With the exception of sweetness, which was rated greater for the $\mathrm{CHO}$ drink compared to the PRO drink $(P=0.038)$, there were no differences in the sensory characteristics of the drinks $(P>0.05)$.

These results demonstrate that the addition of whey protein isolate to a drink ingested 10 min post-exercise reduces energy intake at a subsequent post-exercise meal. This effect was not observed with the ingestion of a sucrose drink. Protein ingestion immediately postexercise might enhance the adaptive response to an exercise training programme (e.g. myofibrillar/mitochondrial protein synthesis) and the present findings suggest that this adaptation might be possible without effecting gross energy intake relative to ingesting nothing postexercise.

1. Aspury NM, Stevenson EJ, Morris P, Taylor MA \& Macdonald IA (2010) Dose-response effect of whey protein preload on within-day energy intake in lean subjects. British Journal of Nutrition 104, 1858-1867.

2. Bertenshaw EJ, Lluch A \& Yeomans MR (2008) Satiating effects of protein but not carbohydrate consumed in a between-meal drink context. Physiology and Behaviour 27, 427-36. 